\title{
Risk management model in patients receiving therapy with biotechnological medications for rheumatoid arthritis in a medical center in Barranquilla, Colombia
}

\begin{abstract}
Introduction: Rheumatoid arthritis is an autoimmune, chronic and inflammatory disease that mainly the synovial membrane of the joints. Clinical features are pain, inflammation, heat and stiffness of the joints.

Objective: Identification of the problems related to the use of biotechnological medicines and the negative results associated with them.

Results: 78 patients $(91.02 \%$ women and $9.8 \%$ men $)$ were included where the most commonly used biological medicines were Etanercept (52.5\%) Adalimumab (14.10) and Tocilizumab (15.3) and Tofacitinib (3.8\%) Rituximab, Golimumab (5.12\%) abatacept (3.84\%) and certolizumab (1.84\%). $96 \mathrm{NCO}$ were identified in 49 patients of which 11 are problems of need, 28 effectiveness problems and 57 safety problems.
\end{abstract}

Conclusion: The identification of medication-related problems and the resolution and prevention of negative results associated with medication allows us to obtain better results in the pharmacotherapy of the patient, improving their quality of life.

Keywords: rheumatoid arthritis, remission, DAS28, biological therapy
Volume 8 Issue I - 2020

\author{
González J,' Durán $M{ }^{2}$ Durán J,, Manrique \\ E,4 Palacio B, ${ }^{4}$ Pereira I, ${ }^{5}$ Caballero E, ${ }^{5}$ Cabas \\ $\mathrm{E}^{6}$ \\ 'QF/MSc/Profesor, Universidad del Atlántico, Colombia \\ ${ }^{2} \mathrm{PhD} / \mathrm{MSc} /$ Profesor, Universidad de Cartagena, Colombia \\ ${ }^{3} \mathrm{IQ} / \mathrm{MSc} /$ Professor, Universidad libre, GEA research group, \\ Colombia \\ ${ }^{4}$ MD/MSc, Universidad de Cartagena, Colombia \\ ${ }^{5}$ Student Universidad del Atlántico, GITOXALQI research group, \\ Colombia \\ MD/ESp/Universidad Libre, Colombia
}

Correspondence: Julia Aracelly Gonzalez Puertas, QF/MSc/ Profesor, Universidad del Atlántico, Barranquilla, Colombia, Tel +5731 |3035440,Email juliagonzalez@mail.uniatlantico.edu.co

Received: December 19, 2019 | Published: January 09, 2020

\section{Introduction}

Rheumatoid arthritis (RA) is a condition of multifactorial origin, characterized by inflammation and hyperplasia of the synovial membrane of the diarthrodial joints, predominantly of the hands and feet, in which there is production of autoantibodies, destruction of cartilage and subchondral bone, and it is usually accompanied by systemic manifestations such as nodules, cardiovascular disease and pulmonary involvement. Proper and early management improves the evolution and prognosis of the disease. ${ }^{1}$ The therapy comprises synthetic and biological disease modifying drugs which have serious side effects and, in the case of biological therapy, represents a potential risk of developing infectious diseases and other effects, associated with their mechanism of action. ${ }^{2}$ The main objective of this study is the identification of the drug-related problems (DRP) and classification of negative clinical outcome (NCO) according to their Necessity, Effectiveness and Safety of pharmacological therapy, through the implementation of a risk management program that prevents or minimizes these adverse health outcomes of patients with rheumatoid arthritis.

\section{Materials and methods}

A pharmaceutical care program was implemented using the DADER methodology. The Dader Method is an operative procedure for the provision of pharmacotherapeutic follow-up in any healthcare setting and on any patient. The objective sought with the application of this operating procedure is to create standards of practice that guarantee the efficiency of the service and, above all, the safety of the patient. ${ }^{3}$ A group of patients diagnosed with rheumatoid arthritis who were receiving biological therapy for this disease were followed up in a documented, systematic and continuous manner; to which the service of the pharmaceutical consultation in a specialized health care center of Barranquilla city was offered, during a period between June and November of the year 2019.

The patients had a pharmaceutical history and the data obtained from the pharmacotherapeutic follow-up. They were registered on an electronic basis according to the DADER methodology. A descriptive study was conducted, and the following data were collected: age, sex, comorbidities, indicated biological medication, medications that accompany the treatment of arthritis, medications that are taken for any other cause, DAS 28 (Disease Activity Score in 28 joints ), CRP, ESR, frequency of medication administration, dose, date of onset of biological treatment, method of administration, delays in administration, possible limitations or limitations in relation to biological therapy, (route and frequency of administration, probability of adverse effects, perception of efficacy and safety). The effectiveness of the treatment was measured using the DAS 28 instrument, where values $<2$ : correspond to remission; $\leq 3.2$ : low activity; $>3.2$ : moderate activity and $>5.1$ : high activity, in relation to support variables such as CRP and ESR. The treatment was effective and was controlled if the value of DAS28 indicated remission or low activity. Safety was analyzed by the appearance of adverse effects associated with medications. ${ }^{4}$ Patients with diseases that affect the nervous system, and diseases that compromise the immune system (HIV and tuberculosis) were excluded from the study, as well as another condition that could interfere with the compression and filling of the questionnaires. 


\section{Results}

78 patients $(91.02 \%$ women and $9.8 \%$ men) with an average age of $56.9( \pm 12.70)$ (Table 1) were included. The most commonly used biological medications were Etanercept, Adalimumab and Tocilizumab with $52.5 \%, 14.10$ and 15.3 respectively and Tofacitinib, Rituximab, Golimumab, Abatacept and Certolizumab with 3.8\%, $5.12 \%, 3.84 \%$ and $1.84 \%$ respectively (Figure 1 ). ${ }^{5}$

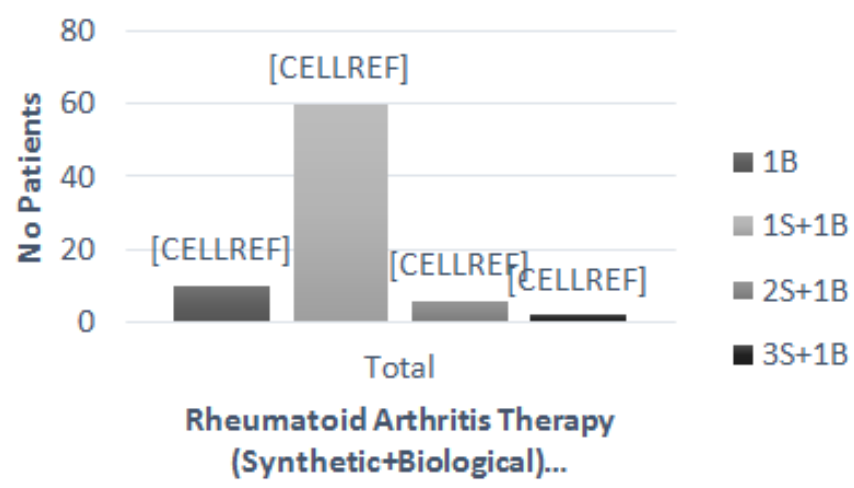

Figure I Biological Drugs administered in Rheumatoid Arthritis Therapy in relation to the number of patients given Pharmaceutical Care.

The following fibromyalgia comorbidities (15.38\%), osteoarthritis (21.7\%), hypertension (23\%), Sjogren's syndrome (16\%), hypothyroidism $(12.82 \%)$, obesity $(6.4 \%)$ were presented, Depression and anxiety (10.26\%) Hypercholesterolemia (9\%), Diabetes (6.41\%), neuropathy (5.1\%) and Osteoporosis (3.8\%) (Table 1).

Table I Characteristics demographic

\begin{tabular}{lll}
\hline & $\mathbf{N}$ & $\%$ \\
\hline Gender & 71 & $91,03 \%$ \\
Female & 7 & $8,97 \%$ \\
Male & & \\
Age & $\pm 57,01$ & \\
Female & $\pm 56,28$ & \\
Male & & \\
Duration of the disease & $\pm 15,12$ & \\
Female & $\pm 16,28$ & \\
Male & & \\
Comorbidities & 18 & $23,08 \%$ \\
Hypertension & 10 & $12,82 \%$ \\
Hypothyroidism & 17 & $21,79 \%$ \\
Arthrosis & 7 & $15,38 \%$ \\
Fibromyalgia & 3 & $16,67 \%$ \\
Sjogren's syndrome & 5 & $10,26 \%$ \\
Anxiety and depression disorder & 8 & $5,13 \%$ \\
Neuropathy & 13 & $6,41 \%$ \\
Diabetes & $5,85 \%$ \\
Hypercholesterolemia & & \\
Osteoporosis & & \\
Obesity & & \\
\hline & & \\
\hline
\end{tabular}

The study found 10 patients (12.8\%) with monotherapy, 60 patients $(76.9 \%)$ who used 1 synthetic and 1 biological where the most frequent was Etanercept-methotrexate, 6 patients (7.69\%) who used two synthetic and 1 biological and 2 patients $(2.56 \%)$ who used 3 synthetic and 1 biological (Figure $2 \& 3$ ). ${ }^{6}$
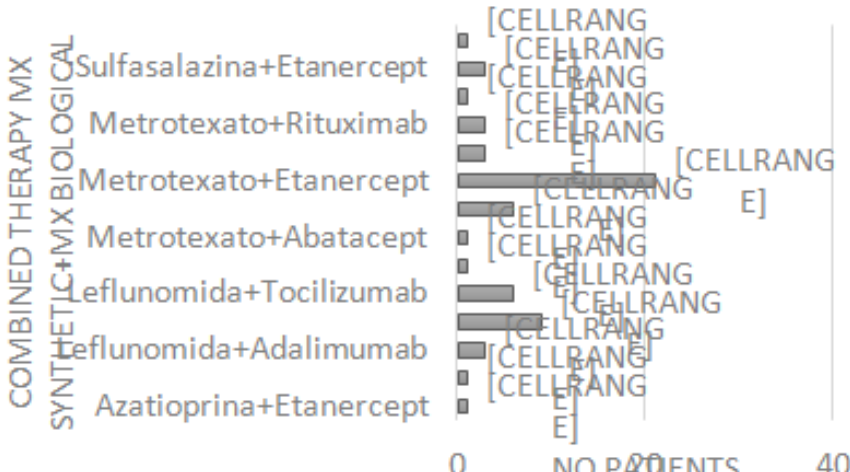

Figure 2 Rheumatoid Arthritis Therapy Administered according to monotherapy IB or combined therapy IS + IB; $2 S+I B ; 3 S+I B$, in relation to the number of patients treated.

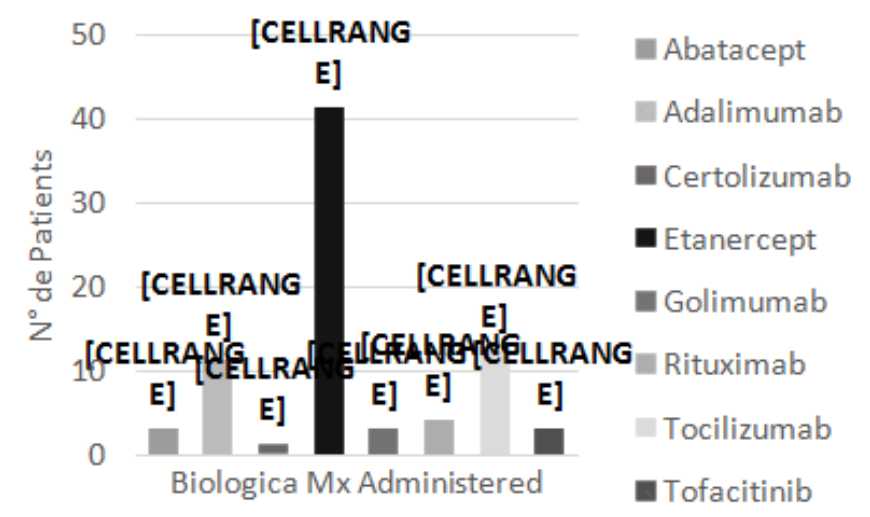

Figure 3 More frequent IS + IB combined therapies in patients presenting with Rheumatoid Arthritis.

When applying DAS 28 it was found that 45 patients $(57.65 \%)$ reported low disease activity, 26 patients $(33.3 \%)$ had moderate disease activity and 7 patients $(8.97 \%)$ high activity of the disease. disease. In turn, $50 \%$ of the patients presented negative CRP values and $25 \%$ of the patients had positive CRP values. ESR was found in normal ranges for $41 \%$ of patients and altered for $31 \%$ of patients (Figure 4, Table 2).

Table 2 Clinical examination to evaluate the disease

\begin{tabular}{lll}
\hline & $\mathbf{N}$ & $\%$ \\
\hline PCR & & \\
$<6$ & 39 & $50,00 \%$ \\
$>6$ & 20 & $25,64 \%$ \\
N/A & 19 & $24,36 \%$ \\
VSG & & \\
$<25$ & 41 & $52,56 \%$ \\
$>25$ & 32 & $41,03 \%$ \\
\hline
\end{tabular}




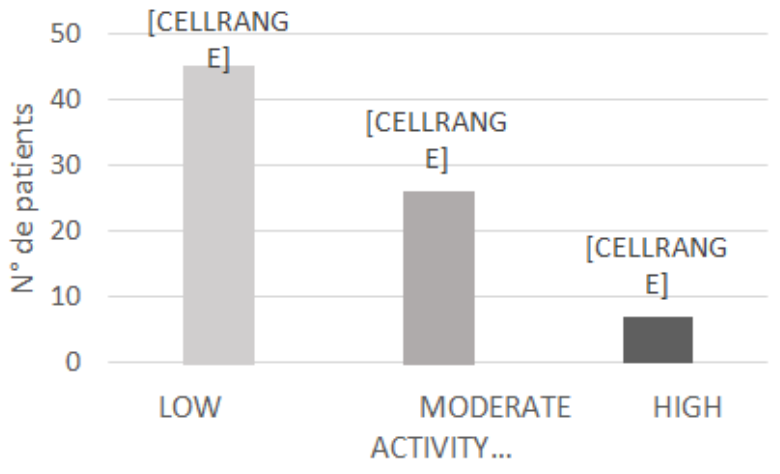

Figure 4 Activity of rheumatoid arthritis according to DAS28, in relation to the patients treated.

96 NCO were identified in 49 patients of which 11 are need problems $(100 \%$ correspond to untreated health problems) and 28 effectiveness problems $(96.43 \%$ are quantitative ineffective and the 3.57 qualitative ineffective), 57 safety problems (31.58\% qualitative insecurities and 68.42 quantitative insecurities) (Table 3).

Table 3 NCO (negative clinical outcome)

\begin{tabular}{lll}
\hline & N & $\%$ \\
\hline NCO & & \\
Need & II & $11,46 \%$ \\
Untreated health problem & II & $100 \%$ \\
Effectiveness & 28 & $29,17 \%$ \\
Qualitative ineffectiveness & I & $3,57 \%$ \\
Quantitative ineffectiveness & 18 & $96,43 \%$ \\
Security & 57 & $59,38 \%$ \\
Qualitative insecurity & 18 & $31,58 \%$ \\
Quantitative insecurity & 39 & $68,42 \%$ \\
\hline
\end{tabular}

55 DRP were found in the categories of: Other (administrative problems due to dispensation) with a percentage of $33.3 \%$, noncompliance $8.97 \%$, probability of adverse effects $(10.26 \%)$, insufficiently treated health problems $(14.10 \%)$, dose and / or inappropriate duration $(2.56 \%)$ and personal characteristics $(1.28 \%)$ (Table 4).

Table 4 DRP (Drug-Related Problems)

\begin{tabular}{lll}
\hline & N & $\%$ \\
\hline DRP & & \\
Personal characteristics & I & $0,78 \%$ \\
Breach & 7 & $5,47 \%$ \\
Dosage, schedule and/or unsuitable duration & 2 & $1,56 \%$ \\
Probability of adverse effect & 8 & $6,25 \%$ \\
Interaction & 73 & $57,03 \%$ \\
Other (administrative problems by dispensation & 26 & $20,31 \%$ \\
Undertreated health problem & II & $8,59 \%$ \\
\hline
\end{tabular}

There were 73 drug interactions distributed in 37 patients, of which 39 were pharmacokinetic interactions ( 37 were moderate and 2 were severe), and 37 were pharmacodynamic interactions ( 32 moderate and 5 severe) (Table 5).

Table 5 Pharmacological interactions

\begin{tabular}{lll}
\hline & N & $\%$ \\
\hline Patients & 37 & \\
Interactions & 73 & \\
Pharmacodynamics & 37 & $50,68 \%$ \\
Moderate & 32 & $43,84 \%$ \\
Serious & 5 & $6,85 \%$ \\
Pharmacokinetics & 39 & $53,42 \%$ \\
Moderate & 37 & $50,68 \%$ \\
Serious & 2 & $2,74 \%$ \\
\hline
\end{tabular}

\section{Discussion}

The majority of patients are female (91\%) and an average age of 56 years \pm 12 was found, very similar to the study conducted by Romero et al.12, in $74 \%$ of the population were women and the Average age was 54 years. $^{7}$

Two of the most commonly used drugs Etanercept (52.55\%) and Adalimumab (14.10\%) belong to the group of antagonistic drugs of tumor necrosis factor alpha which have shown a significant improvement in the course of the disease, by modifying the probability of remission and by reducing or stopping joint destruction. In fact, the Anti-TNF $\alpha$, have a greater efficacy with methotrexate than without it, both from the clinical point of view and from the radiological point of view and it could be evidenced that this was the synthetic one that was most prescribed in the therapies combined. ${ }^{8,9}$

In $57.65 \%$ of the patients categorized in remission and low activity they were in an optimal state of the disease, which is supported by the percentages of the results of CRP and ESR 50\% and $41 \%$ respectively that are within the right ranges. $33.3 \%$ of patients found in moderate activity and $8.9 \%$ in high activity, indicate that they may be presenting inflamed joints and joint pain, which is reflected in the values of CRP (41\%) and ESR (31\%) that were abnormal., ${ }^{410}$ The NCO found are safety and quantitative ineffective due to the 73 interactions that occurred in patients due to the administration of biotechnological drugs.

It is well known that arthritis causes decreased physical activity and therefore increases the degree of disability in patients, which is aggravated by poor adherence to the specialized medical care program; as could be evidenced in the present study. Another problem detected that could explain the large number of patients who are in a moderate activity and perhaps even in a high activity of the disease is the opportunity to dispense the medication; that is to say administrative problems derived from the health sector and that have a negative impact on the success of the pathology control and therefore on the life of the individual. The role of the Pharmaceutical Chemist in the early identification of drug-related problems (DRP) such as drug-drug and pharmacodynamic drug-type interactions helps to make the necessary therapeutic adjustments for pharmacological treatment in patients with rheumatoid arthritis. The identification of 
negative clinical outcome (NCO) of the safety and effectiveness type (therapeutic failure) prevents the patient from running the risk of presenting other health problems associated with the treatment or that the therapeutic objective is not achieved. ${ }^{11,12}$

Studies carried out so far in the field of rheumatology with biological agents have been directed to determine their efficacy and safety. However, with this study it was tried to treat the effectiveness, safety and necessity as clinical practice variables in treatments not only with biological medicines ${ }^{13}$ but also in combination with synthetic medicines, corticosteroids, anti folates, etc. proper for the treatment of rheumatoid arthritis. As an action carried out by the Pharmaceutical Chemist, the implementation of the pharmaceutical interventions carried out with respect to pharmacotherapy is expected, in order to evaluate the possible modifications of the treatment in terms of safety and effectiveness or to improve the positive results achieved, or With respect to the patient so that he has an interest in his treatment, ${ }^{14}$ know the drugs he takes and that their administration is adequate, indicating his use and monitoring of the possible adverse effects that occur, and avoiding latent self-medication that generates interactions serious and moderate to improve the patient's quality of life.

\section{Conclusions}

The implementation of a pharmaceutical care program in patients with rheumatoid arthritis ${ }^{15}$ guided by the pharmaceutical chemist as a pharmacovigilance system is a fundamental part of the risk management derived from the use of biotechnological drugs. With this program, the desired therapeutic objectives can be achieved and, in turn, reduce the safety problems related to biotechnological medications, which favors the proper use of these. ${ }^{16}$

\section{Acknowledgments}

None.

\section{Conflicts of interest}

Authors declare that there is no conflict of interest.

\section{References}

1. Enfermedades Reumaticas. Grupo Cientlfico de la OMS; $1992.76 \mathrm{p}$

2. Guía de Práctica Clínica para la detección temprana, diagnóstico y tratamiento de la artritis reumatoide. Ministerio de Salud y Protección Social-Colciencias; 2014. 23 p.

3. Sabater Hernandez D, Silva Castro M, Faus Dader M. Metodo Dader: Guia de seguimiento farmacoterapeutico. Tercera; 2007. 127 p.
4. Ángel MB. Es la puntuación DAS28 el método más adecuado para estimar la actividad de la artritis reumatoide? Consideraciones clinimétricas y escenarios de simulación. Reumatologia Clinica. 2008;4(5):183-190.

5. Enfermedades autoinmunes (EAI) tienen un origen común [Internet]. Universidad del Rosario; 2010.

6. Camargo Barrios CB, Rivas Ibargüen JE, Quintana-López G. Terapia biológica en la artritis reumatoide temprana: eficacia en la remisión de la enfermedad. Rev Colomb Reumatol. 2017;24(3):164-176.

7. Romero Crespo I, Antón Torres R, Borrás Blasco J, et al. Atención farmacéutica a pacientes con artritis reumatoide y psoriásica en tratamiento con etanercept. Farm Hosp. 2005;29(3):171-176.

8. Plaza JC. Implementación del uso del seguimiento farmacoterapéutico y la farmacogenética en pacientes con artritis reumatoide. Thesis at the university of Granada; 2011.

9. Uribe Botero L, Gomez Rojas L, Amariles Muñoz P. Guía de Actuación Farmacéutica en pacientes con Artritis Reumatoide. Primera; 2010. 31 p.

10. Claudia Mora K, González A, Gerardo Quintana L. Guía de tratamiento de la artritis reumatoide temprana en un Hospital Universitario de Colombia. Rev Colomb Rheumatol. 2008;15(2):79-91.

11. Fallo Terapéutico. Boletin de farmacovigilancia; 2004. 11 p.

12. Ministerio de Salud y proteccion social. Invima Farmacovigilancia. Instituto Nacional de Vigilancia de Medicamentos y Alimentos; 2012.

13. Machado-alba JE, Ruiz AF, Machado-duque ME. Adverse drug reactions associated with the use of disease-modifying anti-rheumatic drugs in patients with rheumatoid arthritis. Value in Health Journal. 2014;36(9):396-401.

14. Figueroa JR, Maldonado CG. Educación al paciente con artritis reumatoide: un nuevo reto a conquistar [Internet]. Revista colombiana de reumatología. 2006;13(1):1-3.

15. Martínez-martínez F, Munoz PA, Faus Dader MJ. Atención Farmacéutica conceptos, procesos y casos prácticos. Ergon; 2008.

16. Hidalgo Martín R, Tames Sánchez L. Atención Farmacéutica: Descripción Del Concepto Y La Aplicación De Sus Actividades Por Parte De Farmacéuticos a Nivel Institucional Y Privado De Los Cantones Centrales De San José Y Cartago Durante El Período De Octubre a Noviembre, 2014; 2014. 8 p. 